\title{
Toward a Systematic Nomenclature for (Neo)Lignanamides
}

\author{
Annemiek van Zadelhoff, Wouter J. C. de Bruijn, Zhongxiang Fang, Emmanuel Gaquerel, \\ Atsushi Ishihara, Danièle Werck-Reichhart, Pangzhen Zhang, Guangxiong Zhou, Maurice C. R. Franssen, \\ and Jean-Paul Vincken*
}

Cite This: J. Nat. Prod. 2021, 84, 956-963

Read Online

ABSTRACT: Phenylalkenoic acid amides, often referred to as phenol amides or hydroxycinnamic acid amides, are bioactive phytochemicals, whose bioactivity can be enhanced by coupling to form dimers or oligomers. Phenylalkenoic acid amides consist of a (hydroxy)cinnamic acid derivative (i.e., the phenylalkenoic acid subunit) linked to an aminecontaining compound (i.e., the amine subunit) via an amide bond. The phenylalkenoic acid moiety can undergo oxidative coupling, either catalyzed by oxidative enzymes or due to autoxidation, which leads to the formation of (neo)lignanamides. Dimers described in the literature are often named after the species in which the compound was first discovered; however, the naming of these compounds lacks a systematic approach. We propose a new

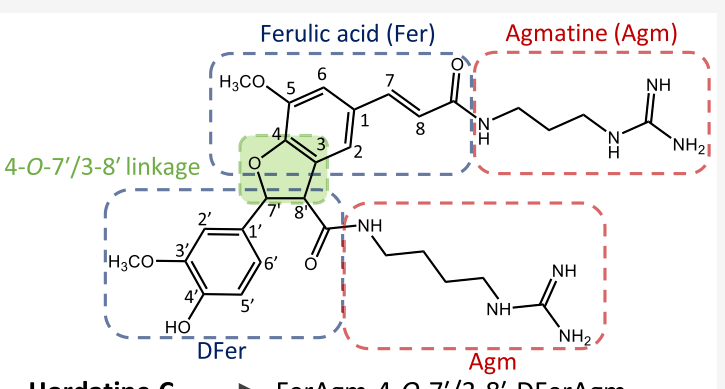

Hordatine C $\longrightarrow$ FerAgm-4-O-7'/3-8'-DFerAgm nomenclature, inspired by the existing system used for hydroxycinnamic acid dimers and lignin. In the proposed systematic nomenclature for (neo)lignanamides, compound names will be composed of three-letter codes and prefixes denoting the subunits, and numbers that indicate the carbon atoms involved in the linkage between the monomeric precursors. The proposed nomenclature is consistent, future-proof, and systematic.

$\mathrm{P}$ henylalkenoic acid amides, often referred to as phenol amides or hydroxycinnamic acid amides, are present in a wide variety of plants and are predominantly found in plant reproductive organs and seeds. Phenylalkenoic acid amides consist of a phenylalkenoic acid subunit (i.e., a cinnamic acid derivative), linked to an amine subunit (Figure 1). ${ }^{1,2}$ Phenylalkenoic acid amides are reported to be bioactive compounds that possess, among others, antiviral, antimicrobial, and insecticidal activities. ${ }^{1,2}$ Upon wounding or microbial stress, plants produce dimeric products of phenylalkenoic acid amides. These compounds, called lignanamides or neolignanamides, are phenylalkenoic acid amides linked to another phenylalkenoic acid amide or a phenylalkenoic acid derivative (e.g., a monolignol). ${ }^{3}$ (Neo)Lignanamides usually possess an even higher biological activity than their monomeric precursors. $^{3-8}$ Examples of increased bioactivity upon oxidative coupling include phenylalkenoic acid-tyramine dimers with higher hepatoprotective and antihyperlipidaemic activity than their monomeric precursor. ${ }^{8,9}$ Furthermore, (neo)lignanamides have been reported to possess antifungal, anti-inflammatory, antineurodegenerative, antioxidant, cytotoxic, and antitumor activities, ${ }^{3}$ which has piqued scientific interest in these compounds.

A wide variety of phenylalkenoic acid amides exist due to the diversity in monomeric units that can be combined. $p$ Coumaric acid, caffeic acid, ferulic acid, and sinapic acid are the most common phenylalkenoic acid subunits; however, other phenylalkenoic acid subunits can be incorporated as well. ${ }^{1}$ An even larger number of different amine subunits can be incorporated, of which tyramine is the most reported amine subunit. ${ }^{1,10}$ From the combination of at least 14 different phenyl subunits and 19 amine subunits, at least 247 different phenylalkenoic acid amides can be formed. Oxidative coupling of these compounds results in further diversification, as different linkage types can be formed and different precursors can be combined. Reported coupling products are either homodimers or heterodimers, consisting of a phenylalkenoic acid amide linked to a different phenylalkenoic acid amide or a phenylalkenoic acid derivative. ${ }^{3}$ Heterodimers with different amine subunits or with different phenyl subunits have both been reported. ${ }^{4,8}$ At least 14 linkage types have been reported and, when only considering the precursors and the linkage types, at least 902538 (247 monomers $\times(247+14$ monolignols $) \times 14$ linkage types $)$ dimers can theoretically be formed, excluding stereoisomers. Dimers are the most common coupling products; however larger oligomers can also be formed. ${ }^{11}$

Received: July 16, 2020

Published: March 31, 2021 


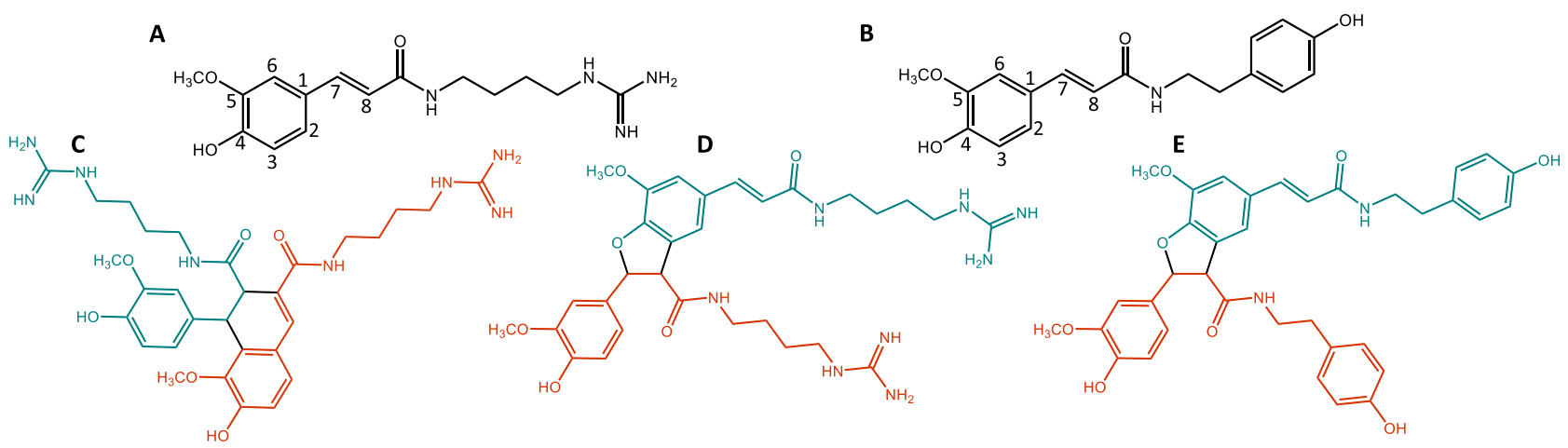

Figure 1. Two examples of phenylalkenoic acid amides, feruloylagmatine (A) and feruloyltyramine (B), and three dimers: two homodimers of feruloylagmatine (C and D) and a homodimer of feruloyltyramine (E). The trivial names currently used for the dimers shown are murinamide $\mathrm{A}$ (structure 54 in Figure S1), hordatine C (33), and grossamide A (26).

Currently, each new (neo)lignanamide is given a trivial name, often derived from the name of the plant in which the compound was first identified, e.g., hordatines from Hordeum and cannabisins from Cannabis.

To indicate different dimers from the same plant species, capital letters are included as part of the compound name. These capital letters, used in alphabetical order, only indicate the order in which compounds were discovered. The capital letters do not indicate specific linkage types or precursors. Thus, there is no system in place for the naming of these compounds. With the growing number of reported dimers, and because the same dimers are found in multiple plant species, ${ }^{12}$ a more systematic nomenclature is needed.

Dimers of the same precursor have completely different names, as is illustrated for feruloyltyramine, for which dimers named lyciumamide $\mathrm{K}$, grossamide A (Figure 1), cannabisins $\mathrm{D}-\mathrm{G}$ and $\mathrm{O}$, hyoscyamide, corydalisin $\mathrm{C}$, and an unnamed dimer have been reported. ${ }^{6,711-16}$ The lack of information embedded in these names is exemplified clearly by cannabisin $\mathrm{G}$ and hyoscyamide, which are the cis- and trans-isomers of the same compound. ${ }^{14,17}$ The main difference between all of the reported feruloyltyramine dimers is the type of linkage between the monomers. The linkage type between the monomers is not indicated, and dimers with a similar linkage type may have completely different names. Lignanamides are formed by lignan-like linkage types, in which both $\beta$-carbon atoms are involved. The smaller group of neolignanamides are formed by neolignan-like linkage types, in which at least one non- $\beta$ carbon is involved. ${ }^{3}$ Murinamide A (Figure 1), lyciumamide I, lyciumamide $\mathrm{J}$, cannabisins $\mathrm{B}-\mathrm{D}$, flavifloramide $\mathrm{A}$, and flavifloramide $\mathrm{B}$ all possess the same linkage type; however, this is not reflected in their names. ${ }^{5,8,15,18}$

The nomenclature used for phenylalkenoic acid amide dimers present in oat is a bit more systematic. For these dimers of avenanthramides (i.e., phenolic anthranilic acid amides), which are called bisavenanthramides and are produced in oat leaves as a mixture of isomers, ${ }^{19}$ the precursor is indicated in the name by using a capital letter and the linkage type is indicated using a number. ${ }^{20}$ However, this nomenclature cannot accommodate heterodimers. In addition, the use of arbitrary numbers and letters forces the reader to search for the corresponding structures. Therefore, a systematic nomenclature based on the chemical structure of the precursors and linkage types would provide significant advantages over the current approach.
One of the enzymes responsible for the oxidative coupling of phenylalkenoic acids, leading to the formation of (neo)lignanamides, is peroxidase. Generally, the peroxidase reaction is not selective to the position or stereochemistry of the generated linkage. An in vitro reaction of avenanthramide B with peroxidase resulted in the generation of a mixture of at least five isomers of bisavenanthramides with different linkage types. ${ }^{20}$ The only isomers with regio- and stereoselective linkages are occasionally isolated from a species, as exemplified by the hordatines in barley (Hordeum vulgare) ${ }^{4}$ and murinamides in Hordeum murinum. ${ }^{5}$ In this context, a nomenclature that can specify the linkages between monomers would be helpful for understanding the regio- and stereoselective biosynthetic reactions.

Thus, a consistent, systematic, and future-proof nomenclature for (neo)lignanamides is proposed. Norlignanamides, coupling products of phenylalkenoic acid amides of which at least one carbon atom is removed upon coupling, will not be incorporated in the proposed nomenclature. ${ }^{21}$ The nomenclature should be applicable for dimers and larger oligomers formed from any phenylalkenoic acid amide and monolignol precursors, to make it a suitable system for existing and to-bediscovered coupling products. The name of each coupling product should indicate the precursors and the linkage type, including relative (cis and trans) and absolute ( $R$ and $S$ ) configuration, to allow for the name to be readily translated to their chemical structure.

We propose a new nomenclature based on the system used for similar linkage types present in dimers of hydroxycinnamic acids (Figure 2) and in the lignin polymer. In these systems the carbon atoms in the phenyl ring are numbered 1 to 6 , and numbering continues with the carbon atoms in the alkenoic

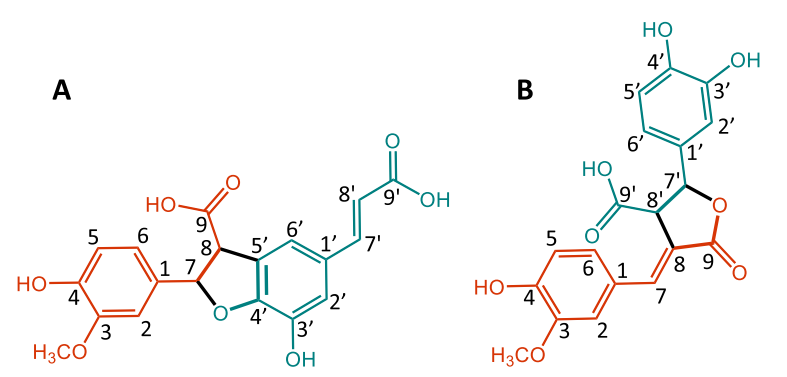

Figure 2. Examples of the numbering used for hydroxycinnamic acid dimers: ferulic acid and caffeic acid connected by $7-\mathrm{O}-4^{\prime}$ and $8-5^{\prime}$ (A) and by $9-\mathrm{O}-7^{\prime}$ and $8-8^{\prime}$ (B) linkages. ${ }^{23}$ 


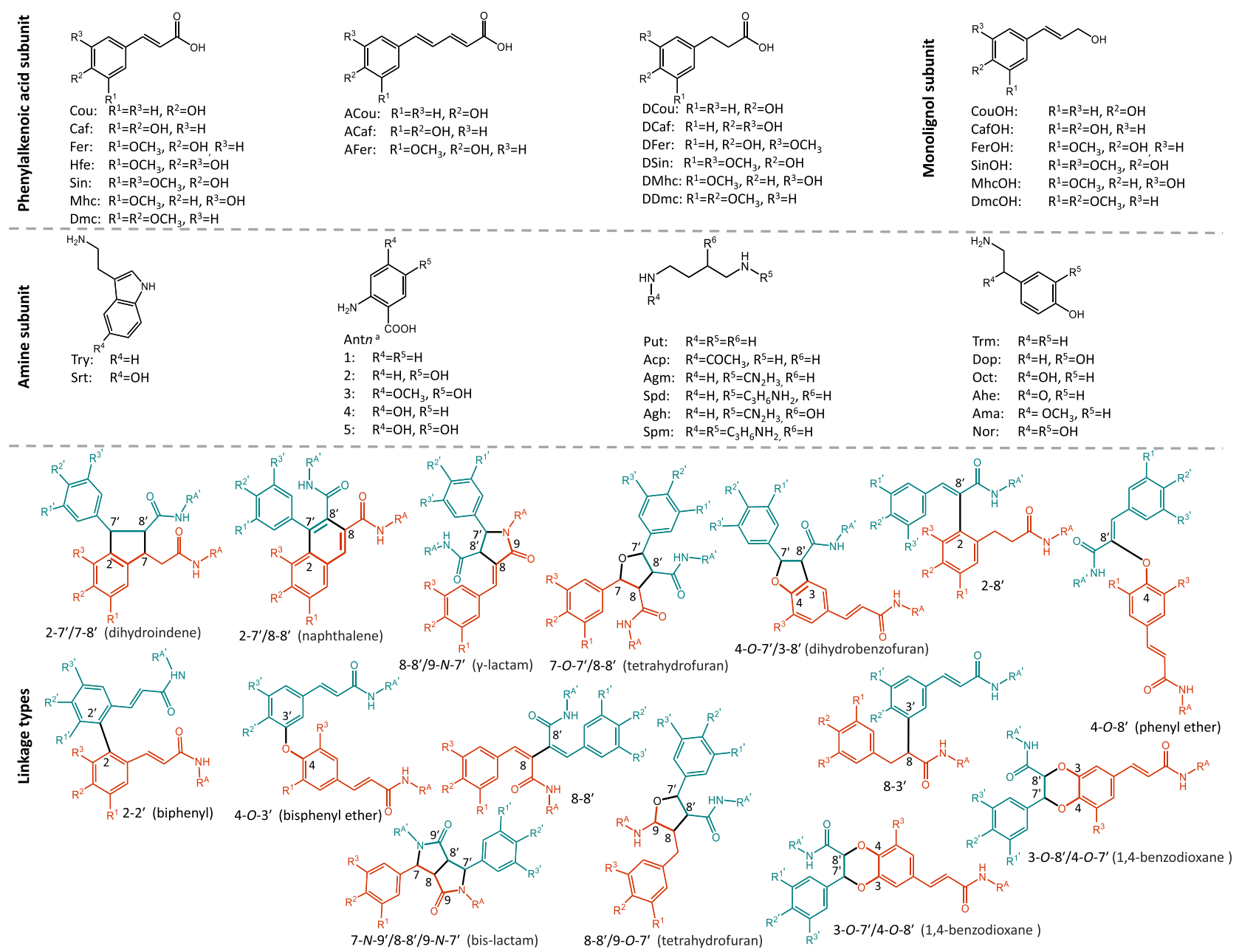

Figure 3. Overview of the different phenylalkenoic acid subunits and amine subunits reported in phenylalkenoic acid amides, the monolignols present in (neo)lignanamides, and the different linkage types occurring in (neo)lignanamides. The $\mathrm{R}^{1}$ and $\mathrm{R}^{2}$ groups might differ from the $\mathrm{R}^{1 \text { ' }}$ and $\mathrm{R}^{2 \prime}$ groups depending on the precursors of the dimer. $\mathrm{R}^{\mathrm{A}}$ indicates the remaining part of the amine group. "For anthranilic acids (Ant) the " $n$ " behind Ant will be replaced by the number of the corresponding anthranilic acid. Structural elements of the different linkage types are given between brackets.

acid moiety attached to the ring; that is, the carbon closest to the phenyl ring is 7 followed by 8 , etc. (Figure 2). ${ }^{22}$ By numbering both precursors and indicating the carbon atoms of one of the precursors with a prime, the carbon atoms involved in the dimerization can be readily and systematically indicated. $^{23,24}$ By indicating the carbon atoms involved, the structure of the coupling product can be described. If either an oxygen or a nitrogen atom is involved in the linkage, the precursor that donates the oxygen or nitrogen atom is indicated without a prime. Figure 3 shows the different phenyl and amine subunits that have been reported as subunits of phenylalkenoic acid amides, monolignols, and all known linkage types for (neo)lignanamides. The abbreviations used in Figure 3 are explained in Table 1.

Some literature abbreviations commonly used for the amine subunits present in phenylalkenoic acid amides overlap with abbreviations used for amino acids (Ser and Tyr). These amino acid three-letter codes have been firmly established in a wide variety of scientific fields, and conjugation of phenylalkenoic acids with amino acids has been reported. ${ }^{25}$ Therefore, to avoid any confusion, new abbreviations are introduced for serotonin (Srt) and tyramine (Trm).
Some of the phenyl and amine group abbreviations contain an extra character. The five types of anthranilic acid groups are numbered one to five in the literature; ${ }^{26}$ therefore this numbering will also be used within the proposed nomenclature. The abbreviation for anthranilic acid is Ant $n$, where the " $n$ " behind "Ant" is replaced by a number to indicate which of the five anthranilic acids is incorporated. Two extra letters are used for the phenyl groups: the prefix "A" represents avenalumic acids containing an extra $\mathrm{CH}=\mathrm{CH}$ group in the side chain of the phenyl group and " $D$ " represents the hydrogenation of the $\mathrm{C}-\mathrm{C}$ double bond in the side chain of dihydrophenylalkenoic acids. Upon (neo)lignanamide formation, often the double bond present in the phenylalkenoic acid is saturated, which should also be indicated by using the prefix "D".

(Neo)Lignanamides can also consist of a phenylalkenoic acid amide linked to a monolignol unit. This group can be named using the same nomenclature; however it should be indicated clearly whether a phenylalkenoic acid amide or a monolignol moiety is incorporated. Monolignols (i.e., cinnamyl alcohols) are indicated by adding "OH" to the abbreviation used for the corresponding phenylalkenoic acid, e.g., "Cou" for $p$-coumaric acid and "CouOH" for $p$-coumaryl 
Table 1. Abbreviations Used for the Phenylalkenoic Acid Subunits, Amine Subunits, and Monolignols ${ }^{1-3,9,10,33,34}$

\begin{tabular}{|c|c|}
\hline \multicolumn{2}{|l|}{ abbreviation } \\
\hline \multicolumn{2}{|c|}{ Phenylalkenoic acid subunits } \\
\hline Cou & $p$-coumaric acid \\
\hline Caf & caffeic acid \\
\hline Fer & ferulic acid \\
\hline Hfe & 5-hydroxyferulic acid \\
\hline $\operatorname{Sin}$ & sinapic acid \\
\hline Mhc & 3-methoxy-5-hydroxycinnamic acid \\
\hline Dmc & 3,4-dimethoxycinnamic acid \\
\hline $\mathrm{ACou}^{a}$ & avenalumic acid \\
\hline ACaf & 5-hydroxyavenalumic acid \\
\hline AFer & 5-methoxyavenalumic acid \\
\hline $\mathrm{DCou}^{b}$ & dihydro- $p$-coumaric acid \\
\hline DCaf & dihydrocaffeic acid \\
\hline DFer & dihydroferulic acid \\
\hline DSin & dihydrosinapic acid \\
\hline \multicolumn{2}{|c|}{ Amine subunits } \\
\hline Try & tryptamine \\
\hline Srt & serotonin \\
\hline Ant $n^{c}$ & anthranilic acid \\
\hline Put & putrescine \\
\hline Acp & acetylputrescine \\
\hline Agm & agmatine \\
\hline Spd & spermidine \\
\hline Agh & hydroxyagmatine \\
\hline Spm & spermine \\
\hline Trm & tyramine \\
\hline Dop & dopamine \\
\hline Oct & octopamine \\
\hline Ahe & 2-amino-1-(4-hydroxyphenyl)ethanone \\
\hline Ama & $\alpha$-(aminomethyl)-4-methoxybenzyl alcohol \\
\hline Nor & noradrenaline \\
\hline \multicolumn{2}{|c|}{ Monolignols } \\
\hline $\mathrm{CouOH}^{d}$ & $p$-coumaryl alcohol \\
\hline $\mathrm{CafOH}$ & caffeyl alcohol \\
\hline FerOH & coniferyl alcohol \\
\hline $\mathrm{SinOH}$ & sinapyl alcohol \\
\hline $\mathrm{MhcOH}$ & 3-methoxy-5-hydroxycinnamyl alcohol \\
\hline $\mathrm{DmcOH}$ & 3,4-dimethoxycinnamic acid \\
\hline
\end{tabular}

${ }^{a} \mathrm{~A}$ represents an extra $\mathrm{CH}=\mathrm{CH}$ group in the alkenoic acid chain. ${ }^{b} \mathrm{D}$ represents hydrogenation of the $\mathrm{C}-\mathrm{C}$ double bond in the alkenoic acid chain. "The " $n$ " behind "Ant" represents one of the five types of anthranilates (see Figure 3 ). ${ }^{d}$ The "OH" indicated in the abbreviation does not indicate hydroxylation of a phenylalkenoic acid but rather the presence of a hydroxy group instead of a carboxylic group.

alcohol. ${ }^{3}$ Lignanamides have been reported where the hydroxy of the monolignol is acetylated, resulting in the formation of an acetoxy group. ${ }^{27}$ In this case the "OH" will be replaced with "OAc", resulting in, for example, "CouOAc".

Using Figure 3 and Table 1 the name of different phenylalkenoic acid amide dimers can be composed. For example, in the proposed system bisavenanthramide B1 (1)

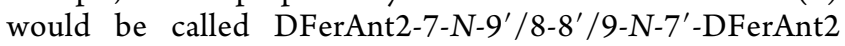
(Figure 4). The first carbon atom denoted in the linkage (i.e., C-7) originates from the precursor first mentioned in the name.

Our new systematic nomenclature is not restricted to dimers and can also be applied to trimers and larger oligomers, as is demonstrated for cannabisin $\mathrm{O}(17)$ : FerTrm-4-O-8'-FerTrm$4^{\prime}-0-7^{\prime \prime} / 3^{\prime}-8^{\prime \prime}$-DFerTrm (Figure 4). At least 80 (neo)-

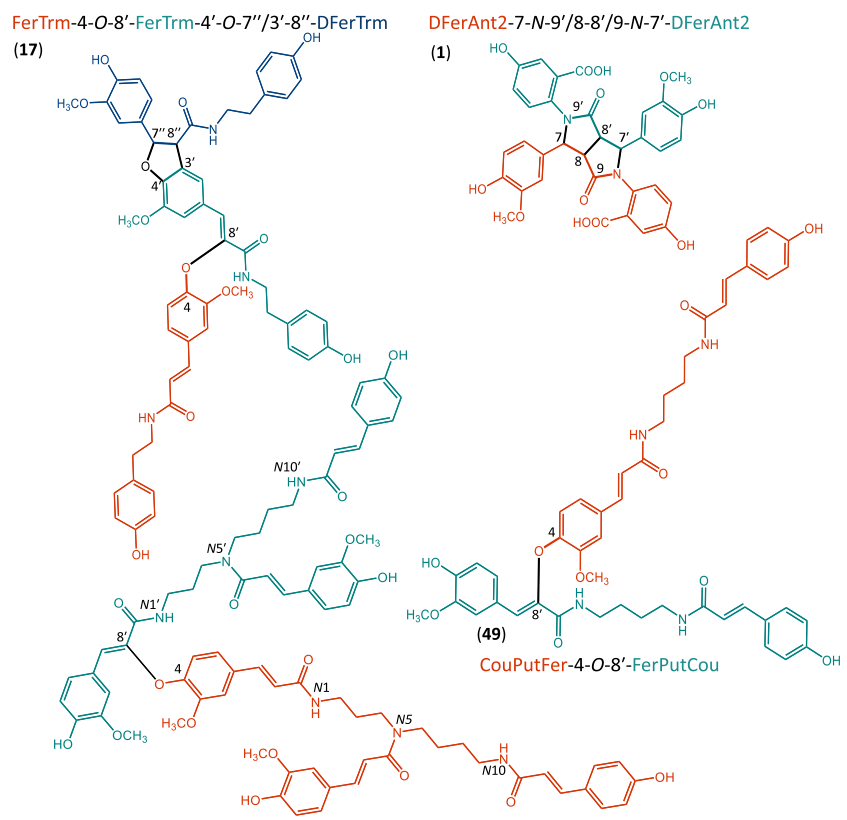

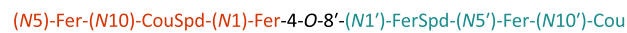

Figure 4. Structural formulas of FerTrm-4-O-8'-FerTrm-4'-O-7" $/ 3^{\prime}$ $8^{\prime \prime}$-DFerTrm (compound 17, see Table 2 and Figure S1), DFerAnt27-N-9'/8-8'/9-N-7'-DFerAnt2 (compound 1), CouPutFer-4-O-8' FerPutCou (compound 49), and (N5)-Fer-(N10)-CouSpd-(N1)-Fer4-O-8'-(N1')-FerSpd-(N5')-Fer- $\left(N 10^{\prime}\right)$-Cou.

lignanamides have been reported. Table 2 provides a comprehensive overview of all reported (neo)lignanamides with their old (trivial) names and new systematic names, and in Figure S1 all of the corresponding (neo)lignanamide structures are shown.

Besides the linkage types shown in Figure 3, several structural variations have been incorporated in the proposed systematic nomenclature. First, simultaneous to dimerization the C-7 can be hydroxylated, which is indicated by adding $\left(7_{\mathrm{OH}}\right)$ to the compound name, as is shown for $\left(7_{\mathrm{OH}}\right)$ DFerAnt2-8-8' $/ 9-N-7^{\prime}$-DFerAnt2. ${ }^{28}$ C-7 can also be substituted with an ethoxy group, which is indicated in a similar way by adding $\left(7_{\mathrm{OEt}}\right) .^{29,30}$ Second, some amine subunits (e.g., putrescine) can be linked to multiple phenyl subunits. Coupling products of such structures will be indicated as illustrated by CouPutFer-4-O-8'-FerPutCou, in which the phenylalkenoic acid subunits (i.e., Fer) involved in the linkage are mentioned before and after mentioning the linkage type (Figure 4). ${ }^{31}$ Polyamines containing spermine or spermidine can be linked to three or even four phenylalkenoic acid moieties. As these amines are not symmetrical, the nitrogen atom to which the phenylalkenoic acid moiety is linked has to be indicated, similarly to how this is currently done for monomers of these compounds. ${ }^{32}$ An example of a spermidine substituted with three phenylalkenoic acids could be $(N 1, N 5)$ Fer-(N10)-CouSpd, a dimer of which, (N5)-Fer-(N10)CouSpd-(N1)-Fer-4-O-8 ${ }^{\prime}-\left(N 1^{\prime}\right)$-FerSpd- $\left(N 5^{\prime}\right)$-Fer- $\left(N 10^{\prime}\right)$ Cou, is shown in Figure 4.

Third, the presence of stereogenic centers of which the configuration ( $R$ or $S$ ) is known can also be indicated in the systematic name. The configuration of stereogenic carbon atoms is mentioned together with the atom to which it refers; for example, if $C-7^{\prime}$ has an $S$ configuration and the C- $8^{\prime}$ has an $R$ configuration, this is indicated as $\left(7^{\prime} S, 8^{\prime} R\right)$, e.g., 
Table 2. Comprehensive Overview of the Former (Trivial or IUPAC) Names and Proposed Systematic Names of all Reported (Neo)Lignanamide Coupling Products ${ }^{a}$

\begin{tabular}{|c|c|c|c|}
\hline no. & proposed systematic name & former name & ref \\
\hline 1 & $\begin{array}{l}\text { DFerAnt2-7-N-9' /8-8 } / 9-N-7^{\prime}- \\
\text { DFerAnt } 2\end{array}$ & Bisavenanthramide B1 & 28 \\
\hline 2 & $\begin{array}{l}\left(7_{\mathrm{OH}}\right)-\mathrm{DFerAnt} 2-8-8^{\prime} / 9-\mathrm{N}-\mathrm{7}^{\prime}- \\
\text { DFerAnt2 }\end{array}$ & Bisavenanthramide $\mathrm{B} 3^{b}$ & 20 \\
\hline 3 & $\begin{array}{l}\left(7_{\mathrm{OH}}\right) \text {-DFerAnt2-8-8 } / 9-N-7^{\prime}- \\
\text { DFerAnt2 }\end{array}$ & Bisavenanthramide $\mathrm{B} 4^{b}$ & 20 \\
\hline 4 & DFerAnt2-7-O-7' / 8-8'-DFerAnt2 & Bisavenanthramide B5 & 20 \\
\hline 5 & FerAnt2-8-8' $/ 9-N-7^{\prime}$-DFerAnt2 & Bisavenanthramide B6 & 20 \\
\hline 6 & CafTrm-2-7' $/ 8-8^{\prime}-$ CafTrm & Cannabisin A & 35 \\
\hline 7 & CafTrm-2-7' $/ 8-8^{\prime}-$ DCafTrm & Cannabisin B & 15 \\
\hline 8 & FerTrm-2-7' /8-8'-DCafTrm & Cannabisin $\mathrm{C}$ & 15 \\
\hline 9 & FerTrm-2-7' $/ 8-8^{\prime}-$ DFerTrm & Cannabisin D & 15 \\
\hline 10 & $\left(7_{\mathrm{OH}}\right)$-DFerTrm-4-O-8' -FerTrm $^{\prime}$ & Cannabisin E & 14 \\
\hline 11 & FerTrm-4-O-8'-FerTrm & Cannabisin $\mathrm{F}^{d}$ & 14 \\
\hline 12 & (E)-FerTrm-8-8'-FerTrm & Cannabisin $\mathrm{G}^{e}$ & 14 \\
\hline 13 & CafTrm-8-8'-CafTrm & 3,3'-Demethyl-cannabisin G & 36 \\
\hline 14 & CafTrm-8-8'-FerTrm & 3-Demethyl-cannabisin G & 36 \\
\hline 15 & CafTrm-3-O-8' /4-O-7'-DCafTrm & Cannabisin $\mathrm{M}$ & 11 \\
\hline 16 & CafTrm-3-O-8' /4-O-7'-DMhcTrm & Cannabisin $\mathrm{N}$ & 11 \\
\hline 17 & $\begin{array}{l}\text { FerTrm-4-O-8'-FerTrm-4'-O-7" / } \\
3^{\prime}-8^{\prime \prime} \text {-DFerTrm }\end{array}$ & Cannabisin $\mathrm{O}$ & 11 \\
\hline 18 & CafTrm-3-O-7' $/ 4-O-8^{\prime}-$ DCafTrm & Cannabisin $\mathrm{Q}$ & 37 \\
\hline 19 & FerTrm-4-O-8'-SinTrm & Corydalisin A & 16 \\
\hline 20 & SinTrm-4-O-8' $-\operatorname{Sin} \operatorname{Trm}$ & Corydalisin B & 16 \\
\hline 21 & SinTrm-2-7' /8-8'-DSinTrm & Corydalisin $\mathrm{C}$ & 16 \\
\hline 22 & FerTrm-4-O-3'-FerTrm & $N$-feruloyl tyramine dimer & 7 \\
\hline 23 & SinTrm-2-7' /8-8'-DFerTrm & Flavifloramide A & 18 \\
\hline 24 & SinTrm-2-7' $/ 8-8^{\prime}-\mathrm{DS}$ in Trm & Flavifloramide B & 18 \\
\hline 25 & $\begin{array}{l}\left(7_{\mathrm{OH}}\right)-\mathrm{DDmcT} \mathrm{rm}-2-7^{\prime} / 8-8^{\prime}- \\
\text { DSinTrm }\end{array}$ & Foveolatamide & 2 \\
\hline 26 & $\begin{array}{l}\text { FerTrm-4-O- } 7^{\prime} / 3-8^{\prime}-\left(7^{\prime} S, 8^{\prime} R\right)- \\
\text { DFerTrm }\end{array}$ & Grossamide $A^{c}$ & 6 \\
\hline 27 & CafTrm-4-O-7 $7^{\prime} / 3-8^{\prime}-$ DCafTrm & 3,3'-Demethyl-grossamide A & 36 \\
\hline 28 & $\begin{array}{l}\text { DFerTrm-7-N-9' } / 8-8^{\prime} / 9-N-7^{\prime}- \\
\text { DFerTrm }\end{array}$ & Heliotropamide & 38 \\
\hline 29 & CafTrm-8-8' /9-N-7'-DCafTrm & 3,3'-Demethyl-heliotropamide & 11 \\
\hline 30 & (Z)-FerTrm-8-8'-FerTrm & Hyoscyamide $^{e}$ & 17 \\
\hline 31 & CouAgm-4-O-7' /3-8'-DCouAgm & Hordatine A & 4 \\
\hline 32 & FerAgm-4-O-7' /3-8'-DCouAgm & Hordatine B & 4 \\
\hline 33 & FerAgm-4-O-7' /3-8'-DFerAgm & Hordatine $\mathrm{C}$ & 30 \\
\hline 34 & $\begin{array}{l}(E) \text {-DFerTrm-7-O-7'/8-8' } \\
\text { DFerOAc }\end{array}$ & Isojacpaniculine $\mathrm{g}^{g}$ & 27 \\
\hline 35 & $\begin{array}{l}\text { (Z)-DFerTrm-7-O-7' } / 8-8^{\prime}- \\
\text { DFerOAc }\end{array}$ & Jacpaniculine $^{g}$ & 27 \\
\hline 36 & FerTrm-8-8' /9-N-7'-DCafTrm & Limoniumin $\mathrm{F}$ & 39 \\
\hline 37 & FerTrm-4-O-7 ${ }^{\prime} / 3-8^{\prime}-$ FerTrm & Limoniumin $\mathrm{G}$ & 39 \\
\hline 38 & CafTrm-2-7' /8-8'-DFerTrm & Limoniumin $\mathrm{H}$ & 39 \\
\hline 39 & SinAcp-2-7' /8-8'-DSinOH & Lycichinenamide & 40 \\
\hline 40 & 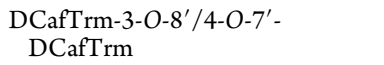 & Lyciumamide D & 8 \\
\hline 41 & $\begin{array}{l}\text { DCafTrm-3-O-7' } / 4-O-8^{\prime}- \\
\text { DCafTrm }\end{array}$ & Lyciumamide $\mathrm{E}$ & 8 \\
\hline 42 & DCafTrm-2-2'-DCafTrm & Lyciumamide $\mathrm{F}$ & 8 \\
\hline 43 & DCafTrm-2-8'-CafTrm & Lyciumamide G & 8 \\
\hline 44 & SinTrm-2-7'/8-8'-DSinOH & Lyciumamide $\mathrm{H}$ & 8 \\
\hline 45 & SinTrm-2-7' /8-8'-DSinAcp & Lyciumamide I & 8 \\
\hline 46 & SinAcp-2-7' / 8-8'-DSinTrm & Lyciumamide J & 8 \\
\hline 47 & DFerTrm-7-O-7' /8-8'-DFerTrm & Lyciumamide $\mathrm{K}$ & 13 \\
\hline 48 & DCafTrm-2-7' /7-8'-DCafTrm & Limoniastramide & 41 \\
\hline 49 & CouPutFer-4-O-8'-FerPutCou & Mariamide A & 31 \\
\hline 50 & SinTrm-2-7' /8-8'-DFerTrm & Melongenamide A & 42 \\
\hline 51 & FerTrm-4-O-7' $/ 3-8^{\prime}$-DFerOct & Melongenamide B & 42 \\
\hline 52 & CouTrm-4-O-8'-CouTrm & Melongenamide C & 42 \\
\hline
\end{tabular}




\section{Table 2. continued}

\begin{tabular}{|c|c|c|}
\hline no. & proposed systematic name & former name \\
\hline 53 & $\begin{array}{l}\text { FerTrm-8'-O-4-FerTrm-2-7" /8-8"- } \\
\left(7^{\prime \prime} R, 8^{\prime \prime} S\right) \text {-DFerTrm }\end{array}$ & Melongenamide $\mathrm{D}^{f}$ \\
\hline 54 & FerOct-4-O-8'-FerOct & Melongenamide E \\
\hline 55 & FerOct-4-O-8'-FerAma & Melongenamide F \\
\hline 56 & FerAma-4-O-8'-FerOct & Melongenamide G \\
\hline 57 & FerAgm-2-7' $/ 8-8^{\prime}$-FerAgm & Murinamide A \\
\hline 58 & FerAgm-8-8'/9-N-7'-DFerAgm & Murinamide B \\
\hline 59 & FerTrm-4-O-7'/3-8'-DSinOAc & Tatarine E \\
\hline 60 & FerTrm-4-O-7'/3-8'-DMhcTrm & Thoreliamide A \\
\hline 61 & CafTrm-3-O-8 $/ 4-O-7^{\prime}-\mathrm{DSinOH}$ & Thoreliamide B \\
\hline 62 & $\begin{array}{l}\text { FerTrm-8'-O-4-FerTrm-2-7" /8-8"- } \\
\text { DFerTrm }\end{array}$ & Thoreliamide $\mathrm{C}^{f}$ \\
\hline 63 & $\begin{array}{l}\text { FerTrm- } 4-O-7^{\prime} / 3-8^{\prime}-\left(7^{\prime} S, 8^{\prime} S\right)- \\
\text { DFerTrm }\end{array}$ & Tribulusamide $\mathrm{A}^{c}$ \\
\hline 64 & FerTrm-4-O-7'/3-8'-DFerAhe & Tribulusamide B \\
\hline 65 & FerTrm-2-7' /8-8'-DFerTrm & Unnamed compound \\
\hline 66 & DFerTrm-8-3'-FerTrm & Unnamed compound \\
\hline 67 & SinTrm-2-7' $/ 8-8^{\prime}-\mathrm{DSinOH}$ & $\begin{array}{l}\text { (3S,4R)-6-hydroxy-4-(4-hydroxy-3,5-dimethoxyphenyl)-3-(hydroxymethyl)- } \mathrm{N} \text {-(4-hydroxyphenethyl)-5,7- } \\
\text { dimethoxy-3,4-dihydronaphthalene-2-carboxamide }\end{array}$ \\
\hline 68 & 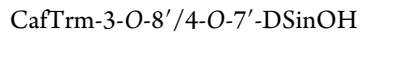 & $\begin{array}{l}\text { (2S,3S,E)-3-[2,3-dihydro-2-(4-hydroxy-3,5-dimethoxyphenyl)-3-(hydroxymethyl)-1,4-benzodioxin-6-yl]-N-[2- } \\
\text { (4-hydroxyphenethyl)ethyl]-2-propenamide }\end{array}$ \\
\hline 69 & $\begin{array}{l}\text { (E)-FerTrm-4-O-7'/3-8'- } \\
\text { DMhcOH }\end{array}$ & $\begin{array}{l}\text { ( } \pm \text { )-(E)-3-(2-(3-hydroxy-5-methoxyphenyl)-3-(hydroxymethyl)-7-methoxy-2,3-dihydrobenzofuran-5-yl)-N-(4- } \\
\text { hydroxyphenethyl)acrylamide }\end{array}$ \\
\hline 70 & (E)-FerTrm-4-O-7'/3-8'-DSinOH & $\begin{array}{l}\text { ( } \pm \text { )-(E)-3-(2-(4-hydroxy-3,5-dimethoxyphenyl)-3-(hydroxymethyl)-7-methoxy-2,3-dihydrobenzofuran-5-yl)-N- } \\
\text { (4-hydroxyphenethyl) acrylamide }\end{array}$ \\
\hline 71 & $\begin{array}{l}\text { (Z)-FerTrm-4-O-7'/3-8'- } \\
\text { DMhcOH }\end{array}$ & $\begin{array}{l}\text { ( } \pm \text { )-(Z)-3-(2-(3-hydroxy-5-methoxyphenyl)-3-(hydroxymethyl)-7-methoxy-2,3-dihydrobenzofuran-5-yl)-N-(4- } \\
\text { hydroxyphenethyl)acrylamide }\end{array}$ \\
\hline 72 & (Z)-FerTrm-4-O-7'/3-8'-DSinOH & $\begin{array}{l}\text { ( } \pm \text { )-(Z)-3-(2-(4-hydroxy-3,5-dimethoxyphenyl)-3-(hydroxymethyl)-7-methoxy-2,3-dihydrobenzofuran-5-yl)-N- } \\
\text { (4-hydroxyphenethyl)acrylamide }{ }^{i}\end{array}$ \\
\hline 73 & $\begin{array}{l}\left.\text { (7 } 7_{\mathrm{OEt}}\right)-\mathrm{DFerOH}-8-8^{\prime} / 9-\mathrm{O}-7^{\prime}- \\
\text { DFerTrm }\end{array}$ & $\begin{array}{l}\text { ( } \pm \text { )-4-(ethoxy(4-hydroxy-3-methoxyphenyl)-methyl)-2-(4-hydroxy-3-methoxyphenyl)- } N \text {-(4-hydroxyphenethyl) } \\
\text { tetrahydrofuran-3-carboxamide }\end{array}$ \\
\hline 74 & FerTrm-4-O-8'-FerTrm & $\begin{array}{l}\text { 3-hydroxy- } N \text {-[2-(4-hydroxyphenyl)ethyl]-7-[4-(2-\{N-[2-(4-hydroxyphenyl)ethyl]carbamoyl }\} \text { xethenyl)-3- } \\
\text { methoxyphenoxy]-4-methoxycinnamamide 4,8"-ether }\end{array}$ \\
\hline 75 & $\begin{array}{l}\text { (E)-CafTrm-3-O-8'/4-O-7'- } \\
\text { DMhcTrm }\end{array}$ & $\begin{array}{l}\text { (2,3-trans)-3-(3-hydroxy-5-methoxyphenyl)-N-(4-hydroxyphenethyl)-7-\{(E)-3-[(4-hydroxyphenethyl)amino]- } \\
\text { 3-oxoprop-1-en-1-yl }\}-2,3 \text {-dihydrobenzo[b] [1,4]dioxine-2-carboxamide }\end{array}$ \\
\hline 76 & $\begin{array}{l}\text { (Z)-CafTrm-3-O-8'/4-O-7'- } \\
\text { DMhcTrm }\end{array}$ & $\begin{array}{l}\text { (2,3-trans)-3-(3-hydroxy-5-methoxyphenyl)-N-(4-hydroxyphenethyl)-7-\{(Z)-3-[(4-hydroxyphenethyl)amino]- } \\
\text { 3-oxoprop-1-en-1-yl }\}-2,3 \text {-dihydrobenzo[b][1,4] dioxine-2-carboxamide }\end{array}$ \\
\hline 77 & SinTrm-2-8'-CafTrm & $\begin{array}{l}\text { (E)-2-(4,5-dihydroxy-2-\{3-[(4-hydroxyphenethyl)amino]-3-oxopropyl\}phenyl)-3-(4-hydroxy-3,5- } \\
\text { dimethoxyphenyl)-N-(4-hydroxyphenethyl)acrylamide }\end{array}$ \\
\hline 78 & SinTrm-2-8'-CafAcp & $\begin{array}{l}\text { (E)-2-(4,5-dihydroxy-2-\{3-[(4-hydroxyphenethyl)amino]-3-oxopropyl }\} \text { phenyl)-3-(4-hydroxy-3,5- } \\
\text { dimethoxyphenyl)- } N \text {-(4-acetamidobutyl)acrylamide }\end{array}$ \\
\hline 79 & FerTrm-2-8'-CafAcp & $\begin{array}{l}\text { (E)-2-(4,5-dihydroxy-2-\{3-[(4-hydroxyphenethyl)amino]-3-oxopropyl\}phenyl)-3-(4-hydroxy-3- } \\
\text { methoxyphenyl)-N-(4-acetamidobutyl)acrylamide }\end{array}$ \\
\hline 80 & SinAcp-2-7' /8-8'-DFerTrm & $\begin{array}{l}\text { (1,2-trans)-N-3-(4-acetamidobutyl)-1-(3,4-dihydroxyphenyl)-7-hydroxy-N-2-(4-hydroxyphenethyl)-6,8- } \\
\text { dimethoxy-1,2-dihydronaphthalene-2,3-dicarboxamide }\end{array}$ \\
\hline
\end{tabular}

${ }^{a}$ All the corresponding structures are shown in Figure S1. In other papers tribulusamide C, and the corresponding succinimide linkage, is reported to be a lignanamide. ${ }^{3,48}$ However, as this compound is not a coupling product of at least one phenylalkenoic acid amide with a phenylalkenoic acid derivative or monolignol, it does not fit the definition of (neo)lignanamides. ${ }^{b, c, d}$ e,f,g,h,i Pairs of cis- and trans-isomers. For ${ }^{b}$ and ${ }^{d}$ these compounds are diastereomers, but their absolute configurations have not been reported. ${ }^{g}$ Thoreliamide $\mathrm{C}$ is reported to be a trans isomer of melongenamide $\mathrm{D}$; however the relative configuration of the ring substituents has not been specified.

FerTrm-4-O-7' $/ 3-8^{\prime}-\left(7^{\prime} S, 8^{\prime} R\right)$-DFerTrm. However, it should be noted that dimers possessing a cyclic junction are mostly present as a racemate in nature; in the literature the cis or trans configuration of their constituents is often not specified. In cases where it is relevant to differentiate between the configuration of $\mathrm{C}=\mathrm{C}$ bonds between isomers, the difference can be indicated using $(E)$ and $(Z)$, respectively, e.g., $(E)$ FerTrm-8-8'-FerTrm.

If, in the future, dimers are discovered that possess a phenyl subunit, an amine subunit, or linkage type that has not been covered in this paper, it can readily be integrated in the proposed nomenclature. For novel phenyl and amine subunits a new three-letter abbreviation should be introduced. Any new linkage types that may be discovered can be described by indicating the connection of the involved carbon atoms and heteroatoms, as is the case for the other linkage types in the system. Substitution of the dimer can be indicated using a subscript following the number or the substituted carbon atom, in the same way as shown for C-7 hydroxylation $\left(7_{\mathrm{OH}}\right)$.

In conclusion, a systematic nomenclature, in which the precursors and linkages types are unambiguously indicated, is proposed for the growing group of (neo)lignanamides.

\section{ASSOCIATED CONTENT}

\section{SI Supporting Information}

The Supporting Information is available free of charge at https://pubs.acs.org/doi/10.1021/acs.jnatprod.0c00792. 
Figure S1: Overview of the structures of the compounds listed in Table 2 (PDF)

\section{AUTHOR INFORMATION}

\section{Corresponding Author}

Jean-Paul Vincken - Laboratory of Food Chemistry, Wageningen University, 6708 WG Wageningen, The Netherlands; (1) orcid.org/0000-0001-8540-4327; Email: jean-paul.vincken@wur.nl

\section{Authors}

Annemiek van Zadelhoff - Laboratory of Food Chemistry, Wageningen University, 6708 WG Wageningen, The Netherlands; (1) orcid.org/0000-0001-9416-8979

Wouter J. C. de Bruijn - Laboratory of Food Chemistry, Wageningen University, 6708 WG Wageningen, The Netherlands; (1) orcid.org/0000-0003-0564-9848

Zhongxiang Fang - School of Agriculture and Food, Faculty of Veterinary and Agricultural Sciences, The University of Melbourne, Parkville, Vic 3010, Australia; (1) orcid.org/ 0000-0002-9902-3426

Emmanuel Gaquerel - Institut de Biologie Moléculaire des Plantes du Centre National de la Recherche Scientifique (CNRS), Université de Strasbourg, Strasbourg 67084, France

Atsushi Ishihara - Faculty of Agriculture, Tottori University, Minami, Tottori 680-8553, Japan; 이이이.org/0000-00021062-2263

Danièle Werck-Reichhart - Institut de Biologie Moléculaire des Plantes du Centre National de la Recherche Scientifique (CNRS), Université de Strasbourg, Strasbourg 67084, France

Pangzhen Zhang - School of Agriculture and Food, Faculty of Veterinary and Agricultural Sciences, The University of Melbourne, Parkville, Vic 3010, Australia; 10 orcid.org/ 0000-0002-9794-2269

Guangxiong Zhou - Guangdong Province Key Laboratory of Pharmacodynamic Constituents of TCM and New Drugs Research, Institute of Traditional Chinese Medicine and Natural Products, College of Pharmacy, Jinan University, Guangzhou 510632, China

Maurice C. R. Franssen - Laboratory of Organic Chemistry, Wageningen University, 6708 WE Wageningen, The Netherlands; (1) orcid.org/0000-0002-3615-9115

Complete contact information is available at: https://pubs.acs.org/10.1021/acs.jnatprod.0c00792

\section{Author Contributions}

The manuscript was written through contributions of all authors. All authors have given approval to the final version of the manuscript.

\section{Notes}

The authors declare no competing financial interest.

\section{ACKNOWLEDGMENTS}

This research received funding from The Netherlands Organisation for Scientific Research (NWO) by an NWO Graduate School Green Top Sectors grant (GSGT.2019.004).

\section{REFERENCES}

(1) Bassard, J.-E.; Ullmann, P.; Bernier, F.; Werck-Reichhart, D. Phytochemistry 2010, 71, 1808-1824.

(2) Meerungrueang, W.; Panichayupakaranant, P. Nat. Prod. Commun. 2016, 11, $1934578 X 1601100127$.
(3) Leonard, W.; Zhang, P.; Ying, D.; Fang, Z. Crit. Rev. Food Sci. Nutr. 2020, 1-11.

(4) Stoessl, A.; Unwin, C. Can. J. Bot. 1970, 48, 465-470.

(5) Ube, N.; Nishizaka, M.; Ichiyanagi, T.; Ueno, K.; Taketa, S.; Ishihara, A. Phytochemistry 2017, 141, 1-10.

(6) King, R. R.; Calhoun, L. A. Phytochemistry 2005, 66, 2468-2473.

(7) Forino, M.; Tartaglione, L.; Dell'Aversano, C.; Ciminiello, P. Food Chem. 2016, 194, 1254-1259.

(8) Chen, H.; Li, Y.-J.; Sun, Y.-J.; Gong, J.-H.; Du, K.; Zhang, Y.-L.; Su, C.-F.; Han, Q.-Q.; Zheng, X.-K.; Feng, W.-S. Fitoterapia 2017, $122,119-125$.

(9) Li, J.-X.; Shi, Q.; Xiong, Q.-B.; Prasain, J. K.; Tezuka, Y.; Hareyama, T.; Wang, Z.-T.; Tanaka, K.; Namba, T.; Kadota, S. Planta Med. 1998, 64, 628-631.

(10) Narváez-Cuenca, C.-E.; Vincken, J.-P.; Gruppen, H. Food Chem. 2012, 130, 730-738.

(11) Yan, X.; Tang, J.; dos Santos Passos, C.; Nurisso, A.; SimõesPires, C. A.; Ji, M.; Lou, H.; Fan, P. J. Agric. Food Chem. 2015, 63, 10611-9.

(12) Yoshihara, T.; Yamaguchi, K.; Takamatsu, S.; Sakamura, S. Agric. Biol. Chem. 1981, 45, 2593-2598.

(13) Noguchi, M.; Mochida, K.; Shingu, T.; Kozuka, M.; Fujitani, K. Chem. Pharm. Bull. 1984, 32, 3584.

(14) Sakakibara, I.; Ikeya, Y.; Hayashi, K.; Okada, M.; Maruno, M. Phytochemistry 1995, 38, 1003-1007.

(15) Sakakibara, I.; Ikeya, Y.; Hayashi, K.; Mitsuhashi, H. Phytochemistry 1992, 31, 3219-3223.

(16) Zhang, B.; Huang, R.; Hua, J.; Liang, H.; Pan, Y.; Dai, L.; Liang, D.; Wang, H. Phytomedicine 2016, 23, 1599-1609.

(17) Ma, C. Y.; Liu, W. K.; Che, C. T. J. Nat. Prod. 2002, 65, 206-9.

(18) Wu, Y.; Zheng, C. J.; Deng, X. H.; Qin, L. P. Helv. Chim. Acta 2013, 96, 951-955.

(19) Okazaki, Y.; Isobe, T.; Iwata, Y.; Matsukawa, T.; Matsuda, F.; Miyagawa, H.; Ishihara, A.; Nishioka, T.; Iwamura, H. Plant J. 2004, $39,560-572$

(20) Okazaki, Y.; Ishizuka, A.; Ishihara, A.; Nishioka, T.; Iwamura, H. J. Org. Chem. 2007, 72, 3830-3839.

(21) Suzuki, S.; Umezawa, T. J. Wood Sci. 2007, 53, 273-284.

(22) Moss, G. Pure Appl. Chem. 2000, 72, 1493-1523.

(23) Arrieta-Baez, D.; Stark, R. E. Phytochemistry 2006, 67, 743753.

(24) Parthasarathi, R.; Romero, R. A.; Redondo, A.; Gnanakaran, S. J. Phys. Chem. Lett. 2011, 2, 2660-2666.

(25) Park, J. B. Int. J. Anal. Chem. 2017, 2017.

(26) Dimberg, L. H.; Sunnerheim, K.; Sundberg, B.; Walsh, K. Cereal Chem. 2001, 78, 278-281.

(27) Henrici, A.; Kaloga, M.; Eicht, E. Phytochemistry 1994, 37, $1637-1640$

(28) Okazaki, Y.; Ishihara, A.; Nishioka, T.; Iwamura, H. Tetrahedron 2004, 60, 4765-4771.

(29) Huang, W.; Li, C.; Wang, Y.; Yi, X.; He, X. Fitoterapia 2017, $117,126-132$.

(30) Gorzolka, K.; Bednarz, H.; Niehaus, K. Planta 2014, 239, $1321-1335$

(31) Qin, N.-B.; Jia, C.-C.; Xu, J.; Li, D.-H.; Xu, F.-X.; Bai, J.; Li, Z.L.; Hua, H.-M. Fitoterapia 2017, 119, 83-89.

(32) Bienz, S.; Detterbeck, R.; Ensch, C.; Guggisberg, A.; Häusermann, U.; Meisterhans, C.; Wendt, B.; Werner, C.; Hesse, M. Alkaloids, Chem. Pharmacol. 2002, 58, 83-338.

(33) Yang, B.-Y.; Yin, X.; Liu, Y.; Ye, H.-L.; Zhang, M.-L.; Guan, W.; Kuang, H.-X. Phytochem. Lett. 2019, 30, 160-164.

(34) Ge, F.; Tang, C.-P.; Ye, Y. Helv. Chim. Acta 2008, 91, 10231030.

(35) Sakakibara, I.; Katsuhara, T.; Ikeya, Y.; Hayashi, K.; Mitsuhashi, H. Phytochemistry 1991, 30, 3013-3016.

(36) Lesma, G.; Consonni, R.; Gambaro, V.; Remuzzi, C.; Roda, G.; Silvani, A.; Vece, V.; Visconti, G. L. Nat. Prod. Res. 2014, 28, 18011807. 
(37) Zhou, Y.; Wang, S.; Lou, H.; Fan, P. Phytochem. Lett. 2018, 23, $57-61$.

(38) Guntern, A.; Ioset, J. R.; Queiroz, E. F.; Sñndor, P.; Foggin, C. M.; Hostettmann, K. J. Nat. Prod. 2003, 66, 1550-1553.

(39) Tuohongerbieke, A.; Li, J.; Sabir, G.; Xue-Lei, X.; Hu, M.; Duan, X.; Liu, L.; Tang, D.; Zhu, J.; Aisa, H. Phytochemistry 2021, 184, 112648.

(40) Huang, H.-C.; Chen, L.-C.; Chang, T.-H.; Zhu, T.-F.; Chen, C.L.; Cheng, M.-J.; Chen, J.-J. Chem. Nat. Compd. 2019, 55, 10021006.

(41) Trabelsi, N.; Oueslati, S.; Ksouri, R.; Nassra, M.; Marchal, A.; Krisa, S.; Abdelly, C.; Mérillon, J.-M.; Waffo-Téguo, P. Food Chem. 2014, 146, 466-471.

(42) Sun, J.; Gu, Y.-F.; Su, X.-Q.; Li, M.-M.; Huo, H.-X.; Zhang, J.; Zeng, K.-W.; Zhang, Q.; Zhao, Y.-F.; Li, J. Fitoterapia 2014, 98, 110116.

(43) Feng, X. L.; Li, H. B.; Gao, H.; Huang, Y.; Zhou, W. X.; Yu, Y.; Yao, X. S. Magn. Reson. Chem. 2016, 54, 396-399.

(44) DellaGreca, M.; Previtera, L.; Purcaro, R.; Zarrelli, A. Tetrahedron 2006, 62, 2877-2882.

(45) Chen, F.; Huang, X.-j.; Liang, Q.-p.; Huang, Y.-p.; Lan, T.; Zhou, G.-x. Nat. Prod. Res. 2019, 33, 3378-3382.

(46) Li, Y.-Z.; Tong, A.-P.; Huang, J. Chem. Biodiversity 2012, 9, $769-776$.

(47) Zhang, J. X.; Guan, S. H.; Feng, R. H.; Wang, Y.; Wu, Z. Y.; Zhang, Y. B.; Chen, X. H.; Bi, K. S.; Guo, D. A. J. Nat. Prod. 2013, 76, $51-8$.

(48) Jiao, L.; Zhao, X.; Liu, H.; Ye, X.; Li, Y.; Jiang, Z. Org. Chem. Front. 2016, 3, 470-474. 


\section{University Library}

\section{- M I N E R VA}

\section{A gateway to Melbourne's research publications}

Minerva Access is the Institutional Repository of The University of Melbourne

\section{Author/s:}

van Zadelhoff, A;de Bruijn, WJC;Fang, Z;Gaquerel, E;Ishihara, A;Werck-Reichhart, D;Zhang,

P;Zhou, G;Franssen, MCR;Vincken, J-P

Title:

Toward a Systematic Nomenclature for (Neo)Lignanamides

Date:

2021-03-31

\section{Citation:}

van Zadelhoff, A., de Bruijn, W. J. C., Fang, Z., Gaquerel, E., Ishihara, A., Werck-Reichhart, D., Zhang, P., Zhou, G., Franssen, M. C. R. \& Vincken, J. -P. (2021). Toward a Systematic Nomenclature for (Neo)Lignanamides. JOURNAL OF NATURAL PRODUCTS, 84 (4), pp.956-963. https://doi.org/10.1021/acs.jnatprod.0c00792.

Persistent Link:

http://hdl.handle.net/11343/278371

License:

CC BY-NC-ND 